\title{
The Participation of Neural Crest Derived Mesenchymal Cells in Development of the Epithelial Primordium of the Thymus*
}

\author{
Shigeru Kuratani and Dale E. Bockman \\ Department of Anatomy, Medical College of Georgia, Augusta, Georgia, U.S.A. \\ Received January 16, 1990
}

\begin{abstract}
Summary. The purpose of this study was to correlate the contributions by derivatives of the neural crest with the development of the epithelial primordium of the thymus. The monoclonal antibody $\mathrm{E} / \mathrm{C} 8$ was used to localize derivatives of the neural crest in chick embryos. Neural crest was ablated by microcautery of neural folds. Evaluation of thymic development was carried out on serial sections of embryos sacrificed on the sixth day of incubation. The size of the epithelial thymic primordium was smaller in experimental animals than in shams. E/C8-immunoreactivity was concentrated around the periphery of the primordium. It was determined, by quantifying reaction product using the CoreSCAN computer color analysis program, that the amount of immunoreactivity was decreased after ablation of neural crest. Statistical analysis showed that the quantity of reaction product was positively and significantly correlated with the size of the thymic primordium. It is concluded that mesenchymal derivatives of the neural crest, through participation in the early development of the epithelial primordium, play an important role in thymic development, and therefore with development of the immune system.
\end{abstract}

Many structures in the head and neck develop from mesenchymal cells that come from the neural crest; expansion of this so-called "ectomesenchyme" produces most of the mesenchyme that populates the pharyngeal arches (JOHNSTON, 1966; WESTON, 1970; LE DOUARIN, 1982; NODEN, 1984). The connective tissue capsule and septa of the thymus are derived from ectomesenchyme (LE LIEVVRE and LE DOUARIN, 1975).

Previous studies from this laboratory have shown that ablation of the cranial neural crest causes impaired development of the thymus, when assessed late in embryonic development (BOCKMAN and KIRBY, 1984, 1985). These findings led to the hypothesis that failure of neural crest-derived mesenchyme to interact properly with the epithelial primordium of the thymus led to subsequent failure of the organ to attract and support the differentiation and proliferation of lymphoid cells. It seemed reasonable to use a marker for derivatives of the neural crest to study their interaction with epithelium during the earliest stages of thymus formation. A monoclonal antibody was used for this purpose.

The monoclonal antibody designated "E/C8" was developed by immunizing with chicken dorsal root ganglion cells (CIMENT and WESTON, 1982). The epitope with which it reacts is a protein of 73,000 Daltons which is present not only in nerve tissue and in a subpopulation of cultured neural crest cells, but also within the mesenchyme of pharyngeal arches 3 , 4, and 6 (Ciment and Weston, 1985). The E/C8 immunoreactivity of pharyngeal arch mesenchymal cells is transient. Whereas approximately $90 \%$ of mesenchymal cells in the posterior arches were immunoreactive at four days of incubation, most immunoreactivity was reported to be gone by day six (Ciment and Weston, 1985).

The present study was designed to assess the contributions of E/C8-positive mesenchymal cells to the developing thymus. The mesenchymal cells surrounding the epithelial primordium of the normally developing thymus were shown to be E/C8-immunoreactive. Neural crest ablation decreased immunoreactivity and thymic size, and there was a positive, significant correlation between the amount of immunoreactivity and the size of the thymic primordium.

\footnotetext{
*This study was supported by Grant No. 2332, The Council for Tobacco Research-U.S.A., Inc.
} 


\section{MATERIALS AND METHODS}

Fertilized Arbor Acre chicken eggs (Seaboard Hatcheries, Athens, GA) were incubated at $38^{\circ} \mathrm{C}$ and $95 \%$ humidity. After approximately $30 \mathrm{~h}$ of incubation, a window was produced in the shell, the embryo was stained with neutral red, and the vitelline membrane was carefully torn to allow access to the dorsum of the embryo. Experimental animals were then subjected to ablation of neural crest by removing the top portion of the neural folds between the midotic region and the caudal boundary of the third somites (KIRBY et al., 1983). Ablation was carried out using a microcautery unit at stages 9 or 10 (HAMBURGER and HAMILTON, 1951), corresponding to the presence of 7 to 10 somites. Sham-operated embryos were subjected to all of these procedures except ablation.

Embryos were sacrificed on the sixth day of incubation. They were fixed in Carnoy's fixative and embedded in paraffin by routine procedures. Specimens were oriented to allow parasagittal sections to be cut. Serial sections of $20 \mu \mathrm{m}$ thickness were mounted and deparaffinized, then incubated in $1 \%$ periodic acid in distilled water for $20 \mathrm{~min}$ to eliminate nonspecific peroxidase activity. Subsequently, they were washed three times in phosphate buffered saline $(\mathrm{pH}$ 7.4) containing $1 \%$ Triton X-100 for 10 min each. Sections were next incubated with $\mathrm{E} / \mathrm{C} 8$ antibody coupled with horseradish peroxidase (kind gift of Dr. Gary CimenT) for $90 \mathrm{~min}$ at room temperature. Antibody was diluted $1 / 200$ in phosphate buffered saline

A
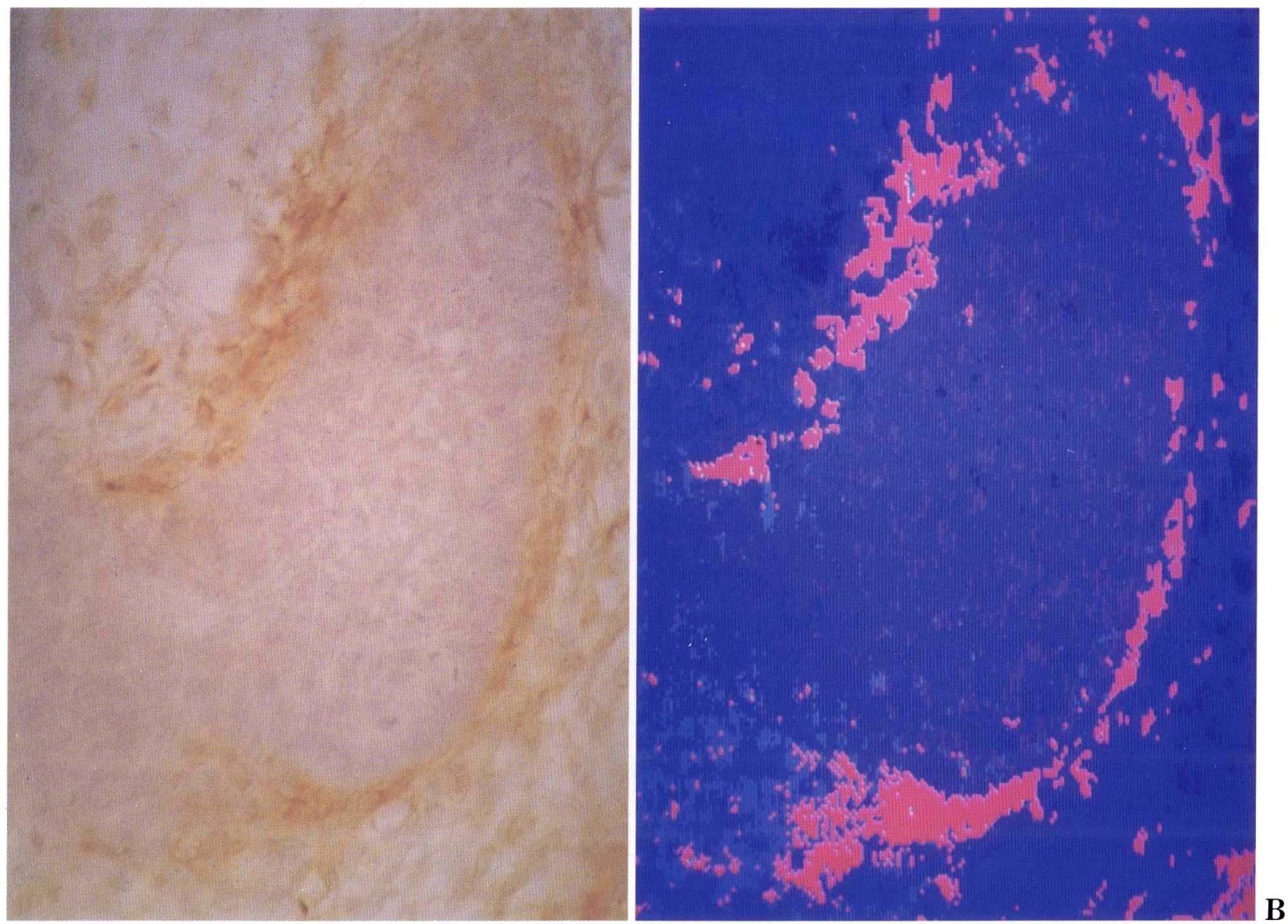

Fig. 1. Epithelial primordium of the thymus from a sham-operated chick. A. The red-brown reaction product localizing the $\mathrm{E} / \mathrm{C}$-immunoreactive cells is concentrated around the periphery of the primordium. Very lightly stained with hematoxylin. B. The same region after scanning for E/C8-immunoreactive cells with the CoreSCAN program, and with the counted pixels superimposed in red. $\times 400$ 
containing $0.3 \%$ Triton $\mathrm{X}-100$ and $0.1 \%$ bovine serum albumin. After rinsing, sections were inbubated for $45 \mathrm{~min}$ at room temperature with $20 \mu \mathrm{g}$ of $3,3^{\prime}$-diaminobenzidine in $300 \mathrm{ml}$ Tris- $\mathrm{HCl}$ buffer $(\mathrm{pH}$ 7.4) containing $300 \mu l$ of $1 \%$ hydrogen peroxide. Some sections were stained lightly with hematoxylin (10 $\mathrm{sec}$ at room temperature) in order to allow visualization of the tissue components without interfering with the reaction product.

Computer-assisted quantification was accomplished using the CoreSCAN program (Extension Systems, Sebastopol, California). Five experimental and six sham embryos were evaluated. For comparing thymic size, the section containing the largest diameter of the epithelial primordium was located, the primordium was outlined, and the number of pixels within the outlined area was determined. The number of pixels was converted mathematically into area $\left(\mathrm{mm}^{2}\right)$. The CoreSCAN program allows the creation of a library of colors which are then searched for in a captured image of the specimen. A library was produced from the colors produced by the reaction product, and the areas containing thymic primordia with surrounding mesenchyme were scanned. The number of positive pixels was then recorded. The number was compared between experimental and sham groups. In addition, the size of primordia was plotted against the number of positive pixels, and the coefficient of correlation calculated.

Statistical assessment was accomplished using Student's t test, with a probability less than 0.05 indicating significance.

\section{RESULTS}

The thymic primordia arise as epithelial outgrowths from the dorsal aspect of pharyngeal pouches 3 and 4 on each side of the chick embryo on day 6 of incubation. Ciment and Weston, (1985) described intense $\mathrm{E} / \mathrm{C}$-immunoreactivity of the majority of mesenchymal cells in the posterior pharyngeal arches of four-day-old chicken embryos. This widespread immunoreactivity diminishes and is not present at day 6. There are scattered $\mathrm{E} / \mathrm{C} 8$-immunoreactive cells in the arches, but most are concentrated around thymic epithelial primordia (Fig. 1A). The colors of the reaction product indicating $\mathrm{E} / \mathrm{C}$-immunoreactive cells are appropriate for analysis using the CoreSCAN program. The result of a scan for immunoreactivity around the same thymic primordium as shown in Figure 1A is illustrated in Figure 1B. After the scan, the positive pixels have been superimposed

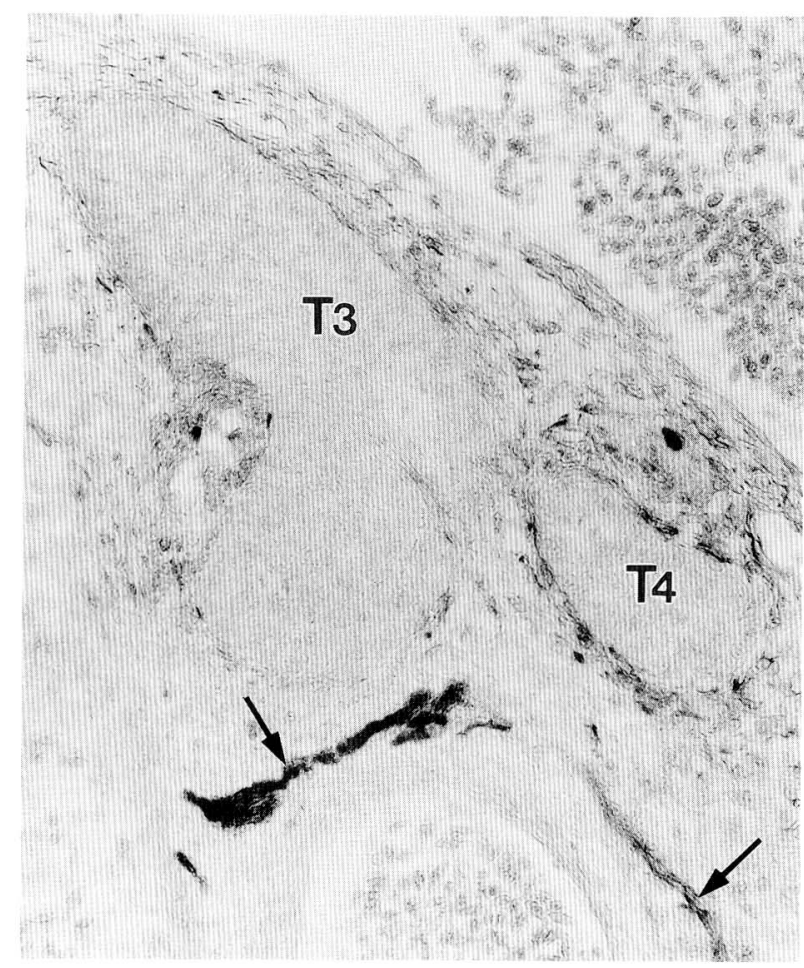

Fig. 2. Parasagittal section of a sham embryo, showing the epithelial primordia of the thymus from the third (T3) and fourth (T4) phąryngeal pouches on one side. The E/ C8-immunoreactivity is concentrated in mesenchymal cells arranged around the periphery of the primordia. Dense, positive neurites are indicated by arrows. $\times 300$

in red over the scanned image. The correlated location of red-brown reaction product and red pixels indicates the reliability of the quantitative procedure.

In all specimens, neurites are identifiable by their intense reactivity and their morphology (Fig. 2). Immunoreactive neurites are present in shams (Fig. 2) and in embryos after ablation of neural crest (Figs. 3, 4). E/C8-immunoreactive mesenchymal cells are distinguishable from neurites because the immunoreactivity is less intense, and because they do not display the linear continuity characteristic of neurites. The instances in which cross sections of neurites in the immediate vicinity of the thymus might be mistaken for a positive mesenchymal cell are minor.

After neural crest ablation, thymic primordia are reduced in size (Fig. 3). They characteristically are represented only by thickenings of the epithelium 
A
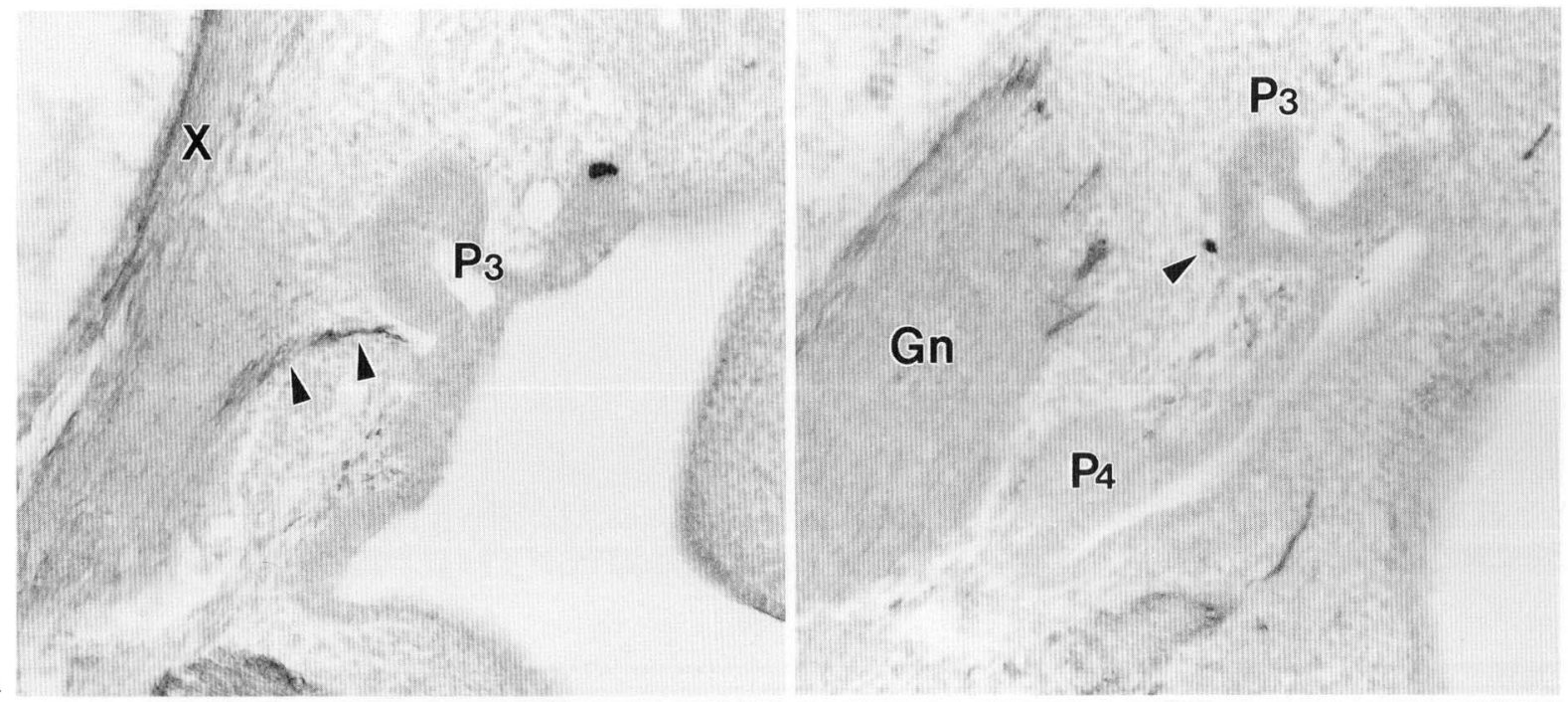

B

C
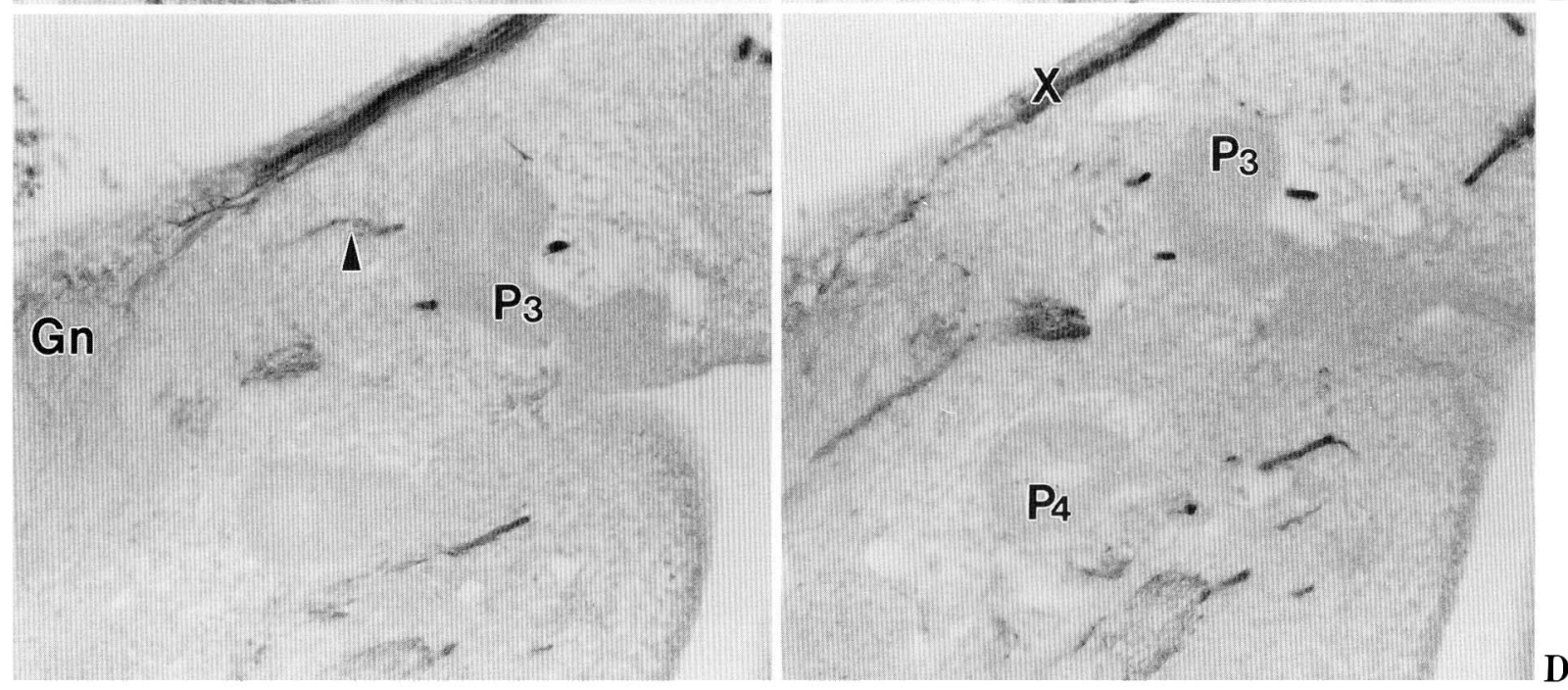

Fig. 3. Parasagittal sections from an embryo subjected to neural crest ablation. The right side is shown in A and $\mathbf{B}$, the left side in $\mathbf{C}$ and $\mathbf{D}$. Compare the small buds of primordial thymus protruding from the pharyngeal pouches $\left(P_{3}, P_{4}\right)$ with the robust primordia seen in Figures 1 and 2. E/C 8 -immunoreactivity is reduced so much that it is hardly visible in black and white pictures. Neurites (arrowheads) may be traced to connections with the vagus nerve $(X)$ and the nodose ganglion $(G n) . \times 150$

extending from the pharyngeal pouch or by small bundles of epithelial cells budding off the pharyngeal pouch. The mean size of thymic primordia in experimental animals $\left(0.014 \mathrm{~mm}^{2} \pm 0.002\right.$ S.E.M. $)$ is significantly less $(p<0.01)$ than that of shams $(0.028$ $\left.\mathrm{mm}^{2} \pm 0.003\right)$.

Furthermore, neural crest ablation leads to decreased $\mathrm{E} / \mathrm{C} 8$-immunoreactivity in the vicinity of thymic primordia (Figs. 3,4 ). The decreased immunoreactivity appears to be the result of decreased num- bers and decreased intensity of positive cells. Quantitative estimation of immunoreactivity reveals that it is significantly less $(\mathrm{p}<0.02)$ in neural crest-ablated animals ( 483 pixels \pm 237 S.E.M.) than in shams (2758 pixels \pm 674$)$. In addition, the immunoreactivity may be distributed differently in experimental animals (Fig. 4). Instead of the heaviest reaction product being concentrated around the thymic primordium, it may be located in the interval between pharyngeal pouches. 


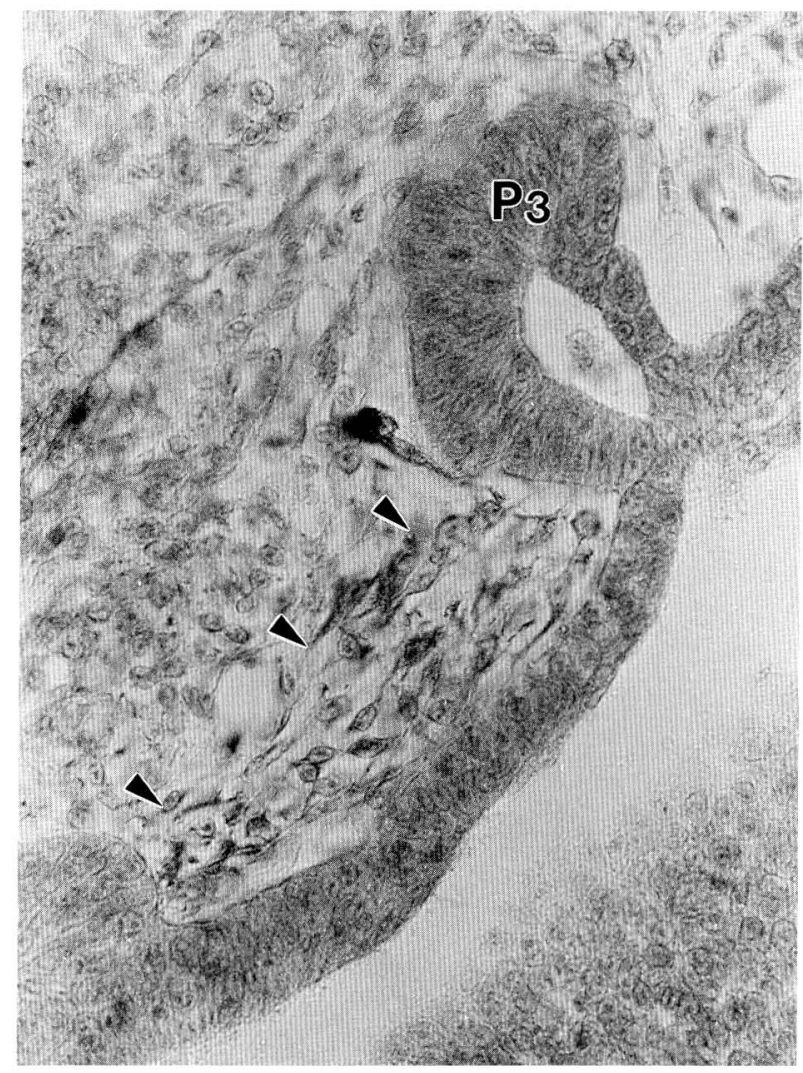

Fig. 4. Region from the same experimental animal as shown in Figure 3. The region of heaviest E/C8-immunoreactivity, indicated by arrowheads, is in the interval between pharyngeal pouches $\left(P_{3}\right)$, rather than surrounding the thymic primordium. $\times 400$

The correlation of the quantity of $\mathrm{E} / \mathrm{C} 8$-positive material with the size of thymic primordia is demonstrated in Figure 5. Smaller thymic size is correlated with less E/C8-immunoreactivity. The coefficient of correlation calculated from this data is 0.88 , indicating a correlation which is positive and significant $(\mathrm{p}<0.001)$.

\section{DISCUSSION}

This study has confirmed that ablation of neural crest in the region which contributes cells to the posterior pharyngeal arches leads to impaired development of the epithelial primordium of the thymus. It has shown for the first time a characteristic clustering of mesenchymal cells which display E/C8-immunoreactivity around the developing thymus. Furthermore, neural

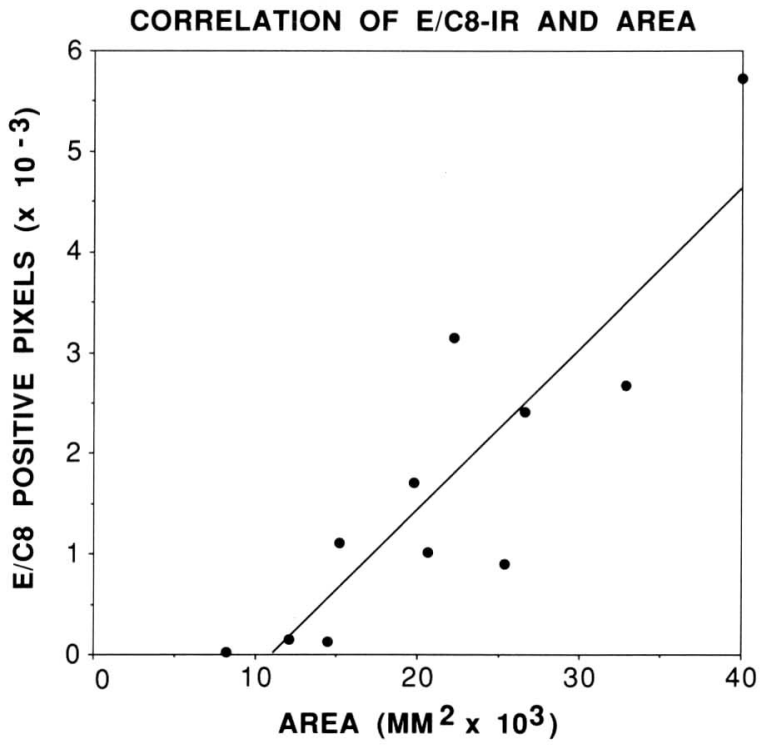

Fig. 5. The plot of thymic area compared with the number of pixels positive for E/C8-immunoreactivity shows a positive, significant correlation between these two entities.

crest ablation causes decreased E/C8-immunoreactivity, and the quantity of immunoreactivity is proportional to thymic size.

The neural crest origin of the E/C8-immunoreactive cells was not formally proven in the present study. However, the fact that most of the mesenchyme in the pharyngeal arches is derived from neural crest (JOHNSTON, 1966; WESTON, 1970; LE DOUARIN, 1982; NoDEN, 1984), most of the mesenchyme in the posterior pharyngeal arches is E/C8positive during development (CIMENT and WESTON, 1985), and neural crest-derived mesenchyme forms the capsule and septa of the thymus (LE LIÈVRE and LE DOUARIN, 1975) argues strongly that the tissue immediately surrounding the thymic primordium is of neural crest origin, and that the immunoreactivity which was measured was the result of localizing a product of neural crest-derived cells. As has been pointed out, other positive neural crest derivatives, 
the neurites, were easily distinguishable from the mesenchyme.

It is reasonable to assume that neural crest-derived mesenchyme (ectomesenchyme) is necessary to induce and support proliferation and differentiation of the epithelial cells of the pharyngeal endoderm in the third and fourth pouches. AUERBACH (1960) has shown that thymic development in the mouse is dependent upon interaction of epithelium and mesenchyme, and that the mesenchyme from this region is more efficient in supporting thymic development than mesenchyme from other areas. The induction must be interactive; that is, the ectomesenchyme does not have the capacity to cause just any endoderm to become thymic primordium - the epithelium from the third and fourth pharyngeal pouches (in the chick) has the capacity to become thymic primordium when ectomesenchyme is present in the appropriate amounts and at the appropriate time.

There can be little doubt that the ectomesenchyme that surrounds the primordial thymus participates in the formation of the definitive thymus as described by LE LIÈVRE and LE DOUARIN (1975). The mature connective tissue derivatives of the neural crest become the septa separating thymic lobules and the sheaths surrounding penetrating blood vessels. It seems that, in addition to this structural role, there is a process by which full differentiation of epithelial potential is regulated by neural crest-derived tissue. This function probably is important during the time when the epithelial primordium is forming. Whether cell-cell contact and/or soluble factors acting at a distance are responsible for the regulation remains to be determined.

Ablation of neural crest causes abnormal development of the heart and great vessels (KIRBY et al., 1983; KIRBY, 1987). We have recently shown that neural crest ablation causes defects, very early in development, of the pharyngeal arch vessels, and that these changes are correlated with a decreased quantity of mesenchyme in the pharyngeal arches (BocK. MAN et al., 1989). Abnormal development of parathyroid glands is another deficiency of neural crest ablation (BOCKMAN and KIRBY, 1984).

There are well-known syndromes in which multiple organs in this group may be affected. Perhaps the clearest example is the DiGeorge syndrome (HUBER et al., 1967; KRETSCHMER et al., 1968; AMMAN et al., 1982; Couly et al., 1983), in which cardiovascular defects and deficiencies in thymus and parathryoids form part of a characteristic pattern. Other conditions in this class include the fetal alcohol syndrome (AMMAN et al., 1982; DAFT et al., 1986), and the defects described in the babies of women who have ingested 13-cis retinoic acid during early pregnancy (LAMMER et al., 1986). The experimental results obtained after neural crest ablation have led to the suggestion that syndromes of this kind are the result of improper development and interactions of neural crest (Couly et al., 1983; KIRBY and BoCKMAN, 1984).

The findings of the present study support this hypothesis with respect to the thymus. Thus they suggest strongly that thymic development is dependent upon neural crest derivatives, and predicts that one result of insufficient contributions from neural crest in an individual will be immune incompetence.

Acknowledgments. We are grateful to Dr. Gary Ciment for the E/C8 antibody, to Mr. Steve Bockman (Extension Systems, Sebastopol, California) for supplying the CoreSCAN program, to Ms. Donna KUMISKI for technical assistance, and to Ms. Sandra DuNN for secretarial assistance.

\section{REFERENCES}

Amman, A. J., D. W. W ARa, M. J. Cowan, D. J. BarretT and E. R. Stienm: The DiGeorge syndrome and the fetal alcohol syndrome. Amer. J. Dis. Child. 136: 906-908 (1982).

Auerbach, R.: Morphogenetic interactions in the development of the mouse thymus gland. Devel. Biol. 2: 271284 (1960).

Bockman, D. E. and M. L. Kirby: Dependence of thymus development on derivatives of the neural crest. Science 223: 498-500 (1984).

Bockman, D. E. and M. L. KIRBY: Neural crest interactions in the development of the immune system. J. Immunol. 135: 766-768 (1985).

Bockman, D. E., M. E. REDmond and M. L. KIRBY: Alteration of early vascular development after ablation of cranial neural crest. Anat. Rec. 225: 209-217 (1989).

Ciment, G. and J. A. Weston: Early appearance in neural crest and crest-derived cells of an antigenic determinant present in avian neurons. Devel. Biol. 93: 355-367 (1982).

Ciment, G. and J. A. Weston: Segregation of developmental abilities in neural-crest cells; Identification of partially intermediate cell types in the branchial arches of avian embryos. Devel. Biol. 111: 73-83 (1985).

Couly, G., A. Lagrue and C. Griscelli: Le syndrome de DiGeorge, neurocristopathie rhombencephalique exemplaire. Rev. Stomatol. Chir. Maxillofac. 84: 103-108 (1983).

DafT, P. A., M. C. Johnston and K. K. Sulik: Abnormal heart and great vessel development following acute ethanol exposure in mice. Teratology 33: 93-109 (1986). 
Hamburger, V. and H. L. Hamilton: A series of normal stages in the development of the chick embryo. J. Morphol. 88: 49-67 (1951).

Huber, J., P. Cholnoky and H. E. Zoethout: Congenital aplasia of parathyroid glands and thymus. Arch. Dis. Child. 42: 190-192 (1967).

Johnston, M. C.: A radioautographic study of the migration and fate of cranial neural crest cells in the chick embryo. Anat. Rec. 156: 143-146 (1966).

KIRBY, M. L.: Cardiac morphogenesis-Recent research advances. Ped. Res. 21: 219-224 (1987).

KiRbY, M. L. and D. E. Bockman: Neural crest and normal development: A new perspective. Anat. Rec. 209: 1-6 (1984).

Kirby, M. L., T. F. Gale and D. E. StewarT: Neural crest cells contribute to normal aorticopulmonary septation. Science 22: 1059-1061 (1983).

Kretschmer, R., B. SaY, D. Brown and F. S. Rosen: Congenital aplasia of the thymus gland (DiGeorge's syndrome). New Engl. J. Med. 279: 1295-1301 (1968).

Lammer, E. J., D. T. Chen, R. M. Hoar, N. D. Agnish, P. J. Benke, J. T. Braun, C. J. Curry, P. M. Fern hoFf, A. W. GRIX, I. T. LotT, J. M. RichaRd and S. C. Sun: Retinoic acid embryopathy. A new human teratogen and a mechanistic hypothesis. New Engl. J. Med. 313: 837-841 (1986).
Le Douarin, N. M.: The neural crest. Cambridge Univ. Press, London, 1982.

Le LiẼvre, C. S. and N. M. Le Douarin: Mesenchymal derivatives of the neural crest: Analysis of chimeric quail and chick embryos. J. Embryol. Exp. Morphol. 34: 125-154 (1975).

Noden, D. M.: Craniofacial development: New views on old problems. Anat. Rec. 208: 1-13 (1984).

Weston, J. A.: The migration and differentiation of neural crest cells. Adv. Morphol. 8: 41-117 (1970).

Dr. Dale E. Bockman Department of Anatomy Medical College of Georgia Augusta, Georgia 30912-2000 U. S. A. 